\title{
Revisiting Catalyst Structure and Mechanism in Methanol Synthesis
}

\author{
Zhiyi Wu, Jesse Cole ${ }^{1}$, Howard L. Fang, Meifang Qin, and Zhong He* \\ Primus Green Energy, Hillsborough, NJ 08844 USA \\ E-mail: zhe@primusge.com
}

\begin{abstract}
Methanol synthesis is a mature industrial process, where industrial $\mathrm{Cu} / \mathrm{ZnO} / \mathrm{Al}_{2} \mathrm{O}_{3}$ catalyst is commonly used. Howerver, function of the active catalyst component and reaction mechanism is still vague. In this contribution, the function of each catalyst component including the synergy between $\mathrm{Cu}$ and $\mathrm{ZnO}$, reaction mechanism including carbon source of methanol, key intermediates and elementary steps, and kinetics of methanol synthesis and impurities formation are discussed based on the latest literature survey.
\end{abstract}

Keywords: Methanol synthesis, $\mathrm{Cu} / \mathrm{ZnO} / \mathrm{Al}_{2} \mathrm{O}_{3}$, mechanism, kinetics.

\section{$1 \quad$ Introduction}

Global demand for methanol is expected to increase from 60.7 million metric tons (MMT) in 2013 to more than 109 MMT in 2023, with an average annual growth rate of 6 percent (according to research from IHS Markit). As one of the most versatile chemical compounds, methanol is used in numerous applications, including for fuel, solvent, antifreeze and for making biodiesel fuels. Methanol production, however, is currently limited to only a few large-scale plants around the world, resulting in high transportation costs for users who are not located within close proximity to a production facility. Primus Green Energy is a green energy company converting natural gas into syngas through methane reforming and then into methanol. Primus' gas-to-methanol (GTM) STG+ ${ }^{\text {TM }}$ System can produce Grade A/AA methanol and methanol meeting IMPCA specification onsite in any location where the feed gas is available or where methanol is in strong demand.[1].

Methanol synthesis is a key step in utilizing natural gas into valuable chemicals and polymers. Methanol was identified as the major product in hydrogenation of $\mathrm{CO}$ over mixed $\mathrm{Cr}_{2} \mathrm{O}_{3}$ and $\mathrm{ZnO}$ by BASF in 1923 [2]. ICI (now Johnson Matthey) discovered a preparation method of $\mathrm{Cu} / \mathrm{ZnO} / \mathrm{Al}_{2} \mathrm{O}_{3}$ [3] to overcome the intrinsic instability of $\mathrm{Cu}$-based catalysts in 1966, which is still the most popular catalyst in industrial practices for the established methanol synthesis process from syngas. However, the actual function of each catalyst component and reaction mechanism is still not clear. This mini-review article summarizes state-of-the-art research including function of each component in an industrial $\mathrm{Cu} / \mathrm{ZnO} / \mathrm{Al}_{2} \mathrm{O}_{3}$ catalyst, their synergistic effects, and the mechanism and kinetics of methanol synthesis. The mechanism and kinetics of impurities formation are also discussed. Understanding those topics is important for methanol catalyst developers to locate their focuses on chasing a better catalyst which is viable at lower operating temperatures and pressures with less impurity formation. In turn, industry methanol producers benefit better plant economics in commercializing methanol synthesis or other processes where methanol is as an intermediate product.

\section{Function of Catalyst Component}

Understanding the nature of the active sites, for example, on which and what type of components of an

${ }^{1}$ Note: The first and second authors have equal contribution 
industrial $\mathrm{Cu} / \mathrm{ZnO} / \mathrm{Al}_{2} \mathrm{O}_{3}$ catalyst does the reaction of $\mathrm{CO} / \mathrm{CO}_{2}$ and hydrogen take place, is important for synthesis of the catalyst with optimized activity and stability. Although substantial research regarding this question has been ongoing since 1960s, currently it is still in dispute. Proposals for the active sites include $\mathrm{Cu}$ metal surfaces, $\mathrm{Cu}^{0}-\mathrm{Cu}^{+1}, \mathrm{Cu}^{+} / \mathrm{ZnO}$ and $\mathrm{Cu}-\mathrm{ZnO}$ interfacial sites $[4,5]$. However, many recent studies [6] have demonstrated that the methanol production rate linearly correlates with copper surface area in the reduced form. Therefore, methanol synthesis from syngas over $\mathrm{Cu}$ appears to be structure sensitive.

Due to their synergistic effects, $\mathrm{ZnO}$ and $\mathrm{Cu}$ are commonly used in tandem in industry as a cheap and efficient option for the production of methanol from syngas. $\mathrm{ZnO}(<673 \mathrm{~K})$ and $\mathrm{Cu}$ by themselves have a low activity for methanol synthesis. Once paired, the activity increases by several orders of magnitude [7]. Recent studies suggested that distorted (or stepped) metallic $\mathrm{Cu}$ surface is active. However, the synergy between $\mathrm{ZnO}$ and distorted metallic $\mathrm{Cu}$ surface increased the reaction rate even further due to dynamic strong metal support interaction effect resulting in partial coverage of $\mathrm{Cu}$ with $\mathrm{ZnO}_{\mathrm{x}}[8]$. A more recent study by Kuld et al. [9] used a model that enabled the isolation of $\mathrm{Cu}-\mathrm{ZnO}$ interaction through specific size regulation and particular reaction conditions that limited the percent of $\mathrm{H}_{2}$ present to inhibit the reverse water gas shift reaction. It has been determined that $\mathrm{ZnO}$ has a promotional effect on $\mathrm{Cu}$ through the migration of $\mathrm{Zn}$ particles across the surface of $\mathrm{Cu}$ particles to cover a portion of the surface in a sub-monolayer of $\mathrm{Zn}$. This in turn functionalizes this $\mathrm{Cu}$ surface which is exposed directly to the gas stream. $\mathrm{ZnO}$ is essential to the formation of a disordered bulk $\alpha$-alloy phase in the interface between $\mathrm{Cu}$ and $\mathrm{Zn}$. Through further analysis of the $\mathrm{Zn}$ coverage of $\mathrm{Cu}$, it was determined that as the size of the $\mathrm{ZnO}$ particles decreased, the overall coverage of the $\mathrm{Cu}$ surface increased and the relative TOF for methanol increased exponentially with decreasing particle diameter, which is due to improved spillover of the $\mathrm{Zn}$ onto $\mathrm{Cu}$ surfaces. The coverage at which the maximum activity for methanol production is reached is found to be at a Zn coverage quantity of approximately $20 \%$ of the surface of the $\mathrm{Cu}$. Upon reaching higher quantities of $\mathrm{ZnO}$, methanol production decreases as $\mathrm{ZnO}$ is more stable than $\mathrm{Zn}$ metal under the conditions tested and $\mathrm{ZnO}$ can thereby restrict the spillover of the $\mathrm{Zn}$.

To explain these synergistic effects, three main theories have been proposed: (1) active site creation through $\mathrm{Cu} / \mathrm{Zn}$ alloys, (2) morphological synergies, and (3) a hydrogen reservoir formed on $\mathrm{ZnO}$ through hydrogen spillover, which efficiently promotes $\mathrm{CO}_{2}$ conversion when $\mathrm{Cu}$ and $\mathrm{ZnO}$ surfaces are adjacent [7]. All three theories can be explained through $\mathrm{Zn}$ migration creating a bronze-like $\mathrm{Cu}_{\mathrm{x}} \mathrm{Zn}_{(1-\mathrm{x})} \mathrm{O}_{\mathrm{y}}$ active phase which occurs solely on the boundary between $\mathrm{Cu}$ and $\mathrm{ZnO}$ particles [10]. The mechanism that best characterizes this migration is the Kirkendall effect, in which differing diffusion rates between two metallic surfaces causes boundary layer movement between these surfaces, thereby leading to a more uniformly active catalyst and preventing cluster formation of $\mathrm{Cu}$ or $\mathrm{ZnO}$ as illustrated in Figure 1 [7]. The bronze-like active phase of $\mathrm{Cu}_{\mathrm{x}} \mathrm{Zn}_{(1-\mathrm{x})} \mathrm{O}_{\mathrm{y}}$ has been effectively reproduced on mechanical mixtures, coprecipitates and core-shell morphologies. Of these morphologies, core-shell is the most effective for methanol production as it prevents reverse water gas shift and methanol decomposition reactions and through structural effects and thereby achieves 100\% methanol selectivity [10]. Except for the three theories, other theories have been proposed, though most of them are still controversial. For example, Frost suggested that oxygen vacancies are created on $\mathrm{ZnO}$ by Shottky junctions. These junctions are formed through contact between $\mathrm{ZnO}$ and $\mathrm{Cu}$ that promote electron transfer between the conduction band of $\mathrm{ZnO}$ and the Fermi level of $\mathrm{Cu}$. The resulting oxygen vacancies improve the effectiveness of the reduction of the $\mathrm{ZnO}$ and thereby add to its activity as a site [11]. Although this theory has not received much later support, it successfully predicted the activity of other metal/oxide catalysts in later studies [4].

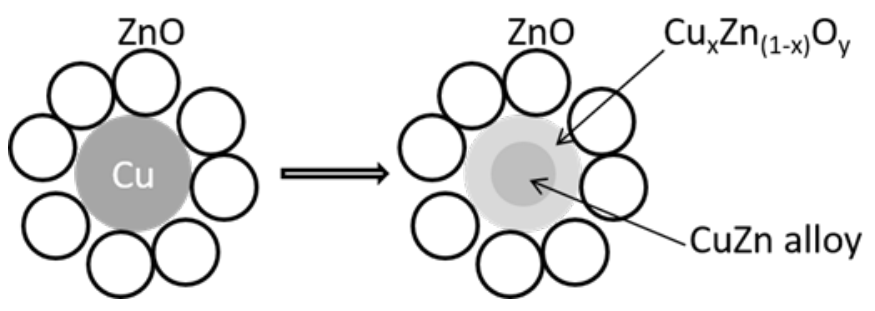

Figure 1. Schematic representation of a mechanical mixture catalyst formation through Kirkendall effect. 
Different from $\mathrm{Cu}$ and $\mathrm{Zn}$, it is generally accepted that $\mathrm{Al}_{2} \mathrm{O}_{3}$ does not participate in methanol synthesis directly. $\mathrm{Al}_{2} \mathrm{O}_{3}$ is commonly used as a structural promoter in commercial methanol synthesis catalysts which effectively improves the solubility of $\mathrm{Zn}$ and thermal stability of the catalyst. However, Liu et al. determined that $\mathrm{Al}_{2} \mathrm{O}_{3}$ weakly participates in the reaction of methanol synthesis from syngas. $\mathrm{Cu}-\mathrm{Zn}-\mathrm{Al}$ catalyst without the use of additional promoters was examined before and after reaction to determine the changes in catalytic performance [12]. The $\mathrm{Cu}-\mathrm{Zn}$ - $\mathrm{Al}$ catalyst had a significant decrease in higher alcohol production when exposed to $523 \mathrm{~K}$ conditions and $120 \mathrm{~h}$ time on stream. However, this decrease in higher alcohol selectivity seemed to be accompanied by an increase in the selectivity of methanol. Impurities, especially higher alcohols, are considered detrimental to methanol suppliers due to additional and tedious removal procedures for these impurities prior to completion of the process. When examined through FT-IR, it was determined that there was a conversion of aluminum species between $\mathrm{AlOOH}$ and $\mathrm{Al}_{2} \mathrm{O}_{3}$ as shown in Figure 2. AlOOH has detrimental effects on the formation of methanol from syngas as the mechanism takes up valuable active sites and causes CO dissociation and promotes the formation of longer chain alcohols by functioning as a bi-functional catalyst. Hence, AlOOH is useful for higher alcohol synthesis but not methanol production. $\mathrm{Al}_{2} \mathrm{O}_{3}$ has an opposite effect and promotes methanol formation and $\mathrm{CO} / \mathrm{CO}_{2}$ hydrogenation leading to more efficient methanol production. More details of higher alcohols and other impurities formation during methanol synthesis will be discussed in the following section.

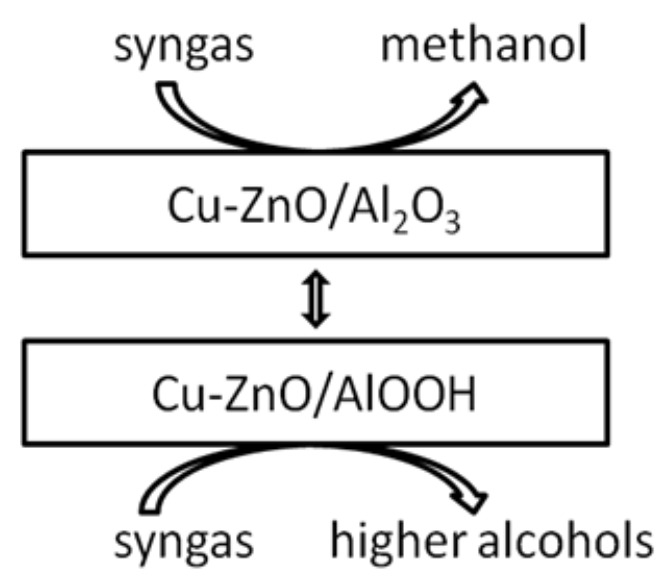

Figure 2. Phase change of $\mathrm{Al}_{2} \mathrm{O}_{3}$ to $\mathrm{AlOOH}$ resulting in suppression of methanol production and a corresponding increase in the rate of higher alcohol formation.

Recent studies have suggested that methanol synthesis takes place mainly on $\mathrm{Cu}$-Zn interfacial sites, where $\mathrm{Cu}$ is partly covered by $\mathrm{Zn}$ or formation of $\mathrm{Cu}_{\mathrm{x}} \mathrm{Zn}_{(1-\mathrm{x})} \mathrm{O}_{\mathrm{y}}$ active phase is favored by $\mathrm{Zn}$ migration. To improve the methanol synthesis activity and catalyst stability, $\mathrm{Al}_{2} \mathrm{O}_{3}$ with minimal $\mathrm{AlOOH}$ phase should be used as the catalyst support.

\section{Reaction Mechanisms}

A reaction mechanism describes the overall chemical change using step by step sequence of elementary reactions. Understanding the reaction mechanisms is critical to build the kinetic model properly, which is used to size reactors during plant design, and to maximize plant production during operation when catalyst is aging. Methanol synthesis in $\mathrm{Cu} / \mathrm{ZnO} / \mathrm{Al}_{2} \mathrm{O}_{3}$ involves three reversible reactions: $\mathrm{CO}$ hydrogenation to methanol, (reverse) water-gas shift, and $\mathrm{CO}_{2}$ hydrogenation to methanol. At equilibrium conditions, only two of them describe the equilibrium composition. Equilibrium constants do exist based on the literature survey. The deviation is as high as 1.92, 1.25, and 2.40, respectively for these three reactions due to small differences in Gibbs energy of formation for methanol and CO [13]. Despite the fact that commercial production of methanol started from almost 100 years ago, the 
reaction mechanism remains controversial. Nevertheless, consensus has been reached regarding some key questions, such as the carbon source, reaction intermediates and elementary steps.

\subsection{Carbon Source of Methanol}

In early 1980s, the point of view that CO could be the predominant carbon source prevailed until isotope labeling experiments proved that methanol is synthesized principally from $\mathrm{CO}_{2}[14,15]$. Later, in situ transient kinetic experiments suggested that $\mathrm{CO}$ participates in methanol synthesis via water gas shifts to $\mathrm{CO}_{2}$. Besides, $\mathrm{CO}$ plays the role as the $\mathrm{H}_{2} \mathrm{O}$ scavenger and serves to maintain the highly reduced state of $\mathrm{Cu}$ [4]. Nowadays, it is generally accepted that $\mathrm{CO}_{2}$ is the preferred carbon source for methanol synthesis, at least with $\mathrm{Cu} / \mathrm{ZnO} / \mathrm{Al}_{2} \mathrm{O}_{3}$ catalysts under industrial conditions, though it is suggested from theoretical calculations [16] and isotope tracer experiment results [17] that the preferred carbon source could shift from $\mathrm{CO}_{2}$ to $\mathrm{CO}$ as temperature is decreased.

\subsection{Key Intermediates and Elementary Steps}

From spectroscopic studies it has been proved that the most abundant surface intermediates are formate, formyl, methoxy, among which bidentate formate is the most stable and abundant species with an estimated fractional coverage being about 30-40\%. Formyl is rather unstable and can be readily hydrogenated to form the more stable methoxy species, which can be further hydrogenated to produce methanol [5]. Regarding the elementary steps, three mechanisms, namely the formate mechanism, the reverse water-gas shift reaction (RWGS) mechanism, and the hydrocarboxyl mechanism have been proposed [18] [19], as shown in Figure 3. The formate mechanism suggests that chemisorbed formate on $\mathrm{Cu}$ sites can be produced from reaction of dissociated surface hydrogen and weakly bound $\mathrm{CO}_{2}$. Hydrogenation of the surface formate $\left(\mathrm{HCOO}^{*}\right)$, which is the rate-determining step, produces dioxomethylene $\left(\mathrm{H}_{2} \mathrm{COO}^{*}\right)$. Dioxomethlyene can either lose an oxygen to form formaldehyde or lose a hydroxyl after hydrogenation to form $\mathrm{H}_{2} \mathrm{CO}$, which can be further hydrogenated to form methoxy and methanol.

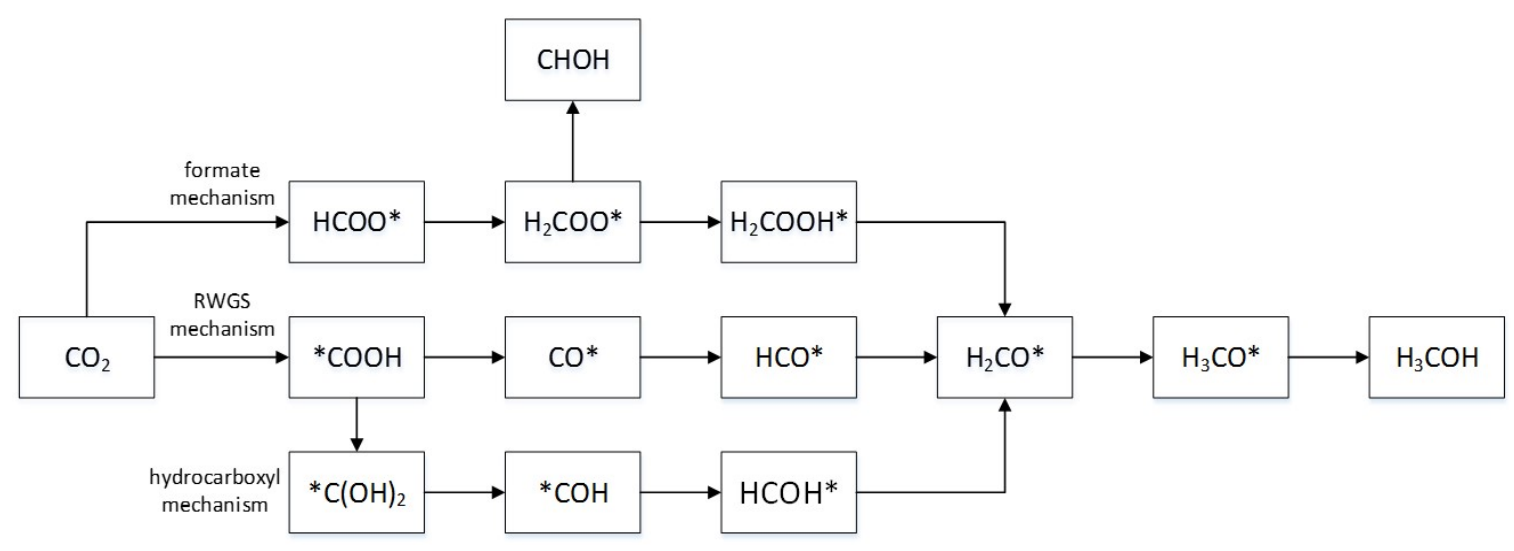

Figure 3. Mechanism and intermediates of methanol synthesis via $\mathrm{CO}_{2}$ hydrogenation over $\mathrm{Cu}$-based catalysts.

Several questions have been raised to argue the validity of this mechanism. First, formaldehyde as a side product has not been detected from methanol synthesis [20, 21]. Second, direct hydrogenation of formate on $\mathrm{Cu}$ surface without the presence of water did not produce methanol [22]. Third, the experimental observed formate hydrogenation kinetics was inconsistent with that of methanol formation [23]. In contrast with the formate mechanism, the RWGS and hydrocarboxyl mechanism suggest that $\mathrm{CO}_{2}$ and hydrogen react to form adsorbed hydrocarboxyl intermediate $\left({ }^{*} \mathrm{COOH}\right)$. In the RWGS route, the hydrocarboxyl loses a hydroxyl to form ${ }^{*} \mathrm{CO}$, which is subsequently hydrogenated to form formyl, methoxy and methanol. In the hydrocarboxyl route, dihydroxylcarbene $\left({ }^{*} \mathrm{C}(\mathrm{OH})_{2}\right)$ is produced via hydrogenation of ${ }^{*} \mathrm{COOH}$. By losing one of the hydroxyl group, ${ }^{*} \mathrm{COH}$ is produced, which will undergo subsequent hydrogenation to form methoxy and methanol. It has been suggested, however, by recent 
calculations [24] that formyl formation by reaction of ${ }^{*} \mathrm{CO}$ and ${ }^{*} \mathrm{H}$ is unlikely. Zhao et al. [19] also suggested that formation of $* \mathrm{H}_{2} \mathrm{CO}$ is much more favored than ${ }^{*} \mathrm{HCOH}$ by hydrogenation of $* \mathrm{HCO}$, and $* \mathrm{H}_{2} \mathrm{CO}$ will readily desorb to form formaldehyde, which has not been observed experimentally. Thus, the RWGS mechanism is also questionable. The same group suggested that formation of hydrocarboxyl species can be kinetically more favorable than formate in the presence of water. This is consistent with that small amount of water could significantly promote dry $\mathrm{CO}_{2}$ hydrogenation to produce methanol at the beginning of the reaction. While methanol synthesis proceeds via the hydrocarboxyl route, the dominant surface formate is spectator rather than intermediate species [25].

\subsection{Kinetics of Methanol Synthesis}

Building kinetic model of methanol synthesis is critical in sizing reactors and control temperatures in industrial practice. Up to now, most of the kinetic models of methanol synthesis in literature are based on the formate mechanism. Some of them using commercial $\mathrm{Cu} / \mathrm{ZnO} / \mathrm{Al}_{2} \mathrm{O}_{3}$ catalysts under industrial conditions are summarized in Table 1. It should be noted that using fugacities instead of partial pressures is necessary since water and methanol are highly non-ideal at the pressures and temperatures in industrial practice.

\subsection{Mechanism of Impurity Formation}

Modern methanol synthesis catalysts can be highly selective. Methanol selectivity higher than $99.9 \%$ is not uncommon depending on the reaction conditions. Most of the impurities are higher alcohols, predominantly ethanol, propanols and butanols. Esters especially methyl formate and methyl acetate, ketones especially acetone and butanone, ethers, hydrocarbons, acids and aldehydes can also be detected [4]. Higher alcohols are synthesized due to the alkali residues such as $\mathrm{K}^{+}$and $\mathrm{Na}^{+}$remaining in the catalysts from their manufacturing [31], which affects production of formyl species as the key precursor. These alkali cations and their $\mathrm{OH}^{-}$anions serve as the active centers to adsorb and activate $\mathrm{CO}$ and methanol and produce formate [32]. Hydrogenation of the formate produces surface formyl species, and formaldehyde can be produced either from hydrogenation of the formyl species or dehydrogenation of methanol via surface $\mathrm{OH}^{-}$. Nucleophilic attack of the formyl species on formaldehyde produces a C2 precursor. Ethanol can then be produced by hydrogenation of the $\mathrm{C}_{2}$ precursor. Chain growth of alcohol proceeds via nucleophilic attack of formyl either on the $\alpha$ or $\beta$ carbon of the lower alcohol, leading to linear chain growth or branching [33]. With alkali-promoted $\mathrm{Cn} / \mathrm{ZnO} / \mathrm{Al}_{2} \mathrm{O}_{3}$ catalysts, $\beta$-addition can be the dominant path, consistent with the fact that isobutanol selectivity is always higher than other $\mathrm{C}_{4}$ alcohols during methanol synthesis [34]. However, if the catalyst contains nickel or iron either by deposition from carbonyls or catalyst manufacturing, linear alcohols will be dominant with the carbon number following Schulz-Flory distribution as in Fisher-Tropsch synthesis [35, 36].

\subsection{Kinetics of Ethanol Formation}

The distribution and kinetics studies of the impurities are scarce. Calverley et al. [37] reported a kinetics model for the overall rate of higher alcohol synthesis over $\mathrm{K}_{2} \mathrm{CO}_{3}$ doped $\mathrm{Cu} / \mathrm{ZnO} / \mathrm{Cr}_{2} \mathrm{O}_{3}$ catalysts. The Langmuir-Hinshelwood type model is based on surface reactions of formyl species at $280{ }^{\circ} \mathrm{C}$ and $10 \mathrm{MPa}$, which is denoted as equation (1):

$$
r_{\mathrm{HAS}}=\left(\frac{P_{\mathrm{CO}}\left(P_{\mathrm{H}_{2}}\right)^{1 / 2}}{A+B P_{\mathrm{CH}_{3} \mathrm{OH}}}+C P_{\mathrm{CH}_{3} \mathrm{OH}}\left(P_{\mathrm{H}_{2}}\right)^{-3 / 2}+\frac{P_{\mathrm{CO}_{2}}\left(P_{\mathrm{H}_{2}}\right)^{1 / 2}}{D+E P_{C \mathrm{CO}_{2}} / P_{C O}}\right)^{2}
$$




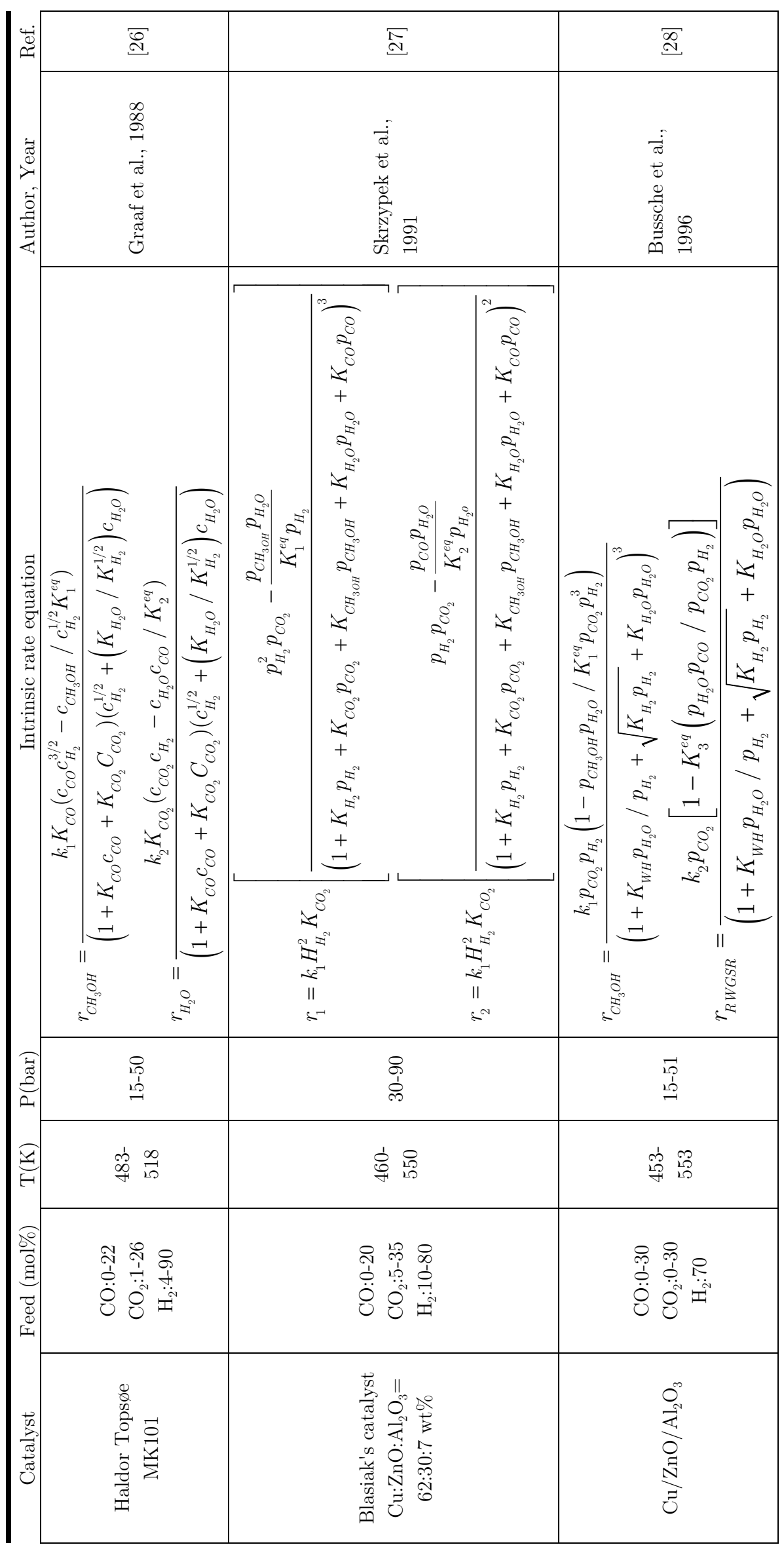




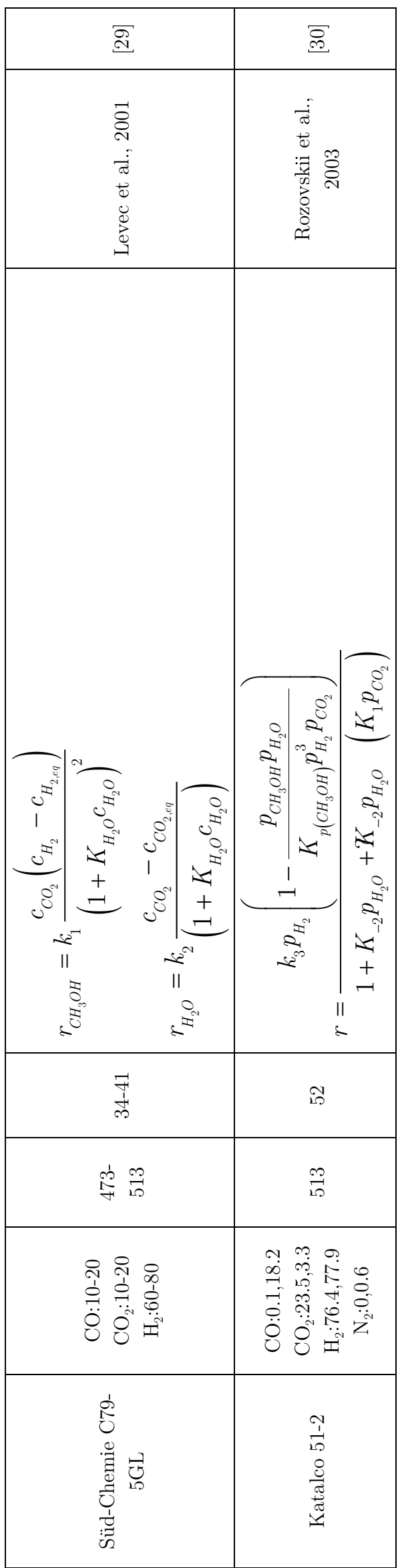


Several factors have been found that affect the amounts of the impurities. The higher alcohol amounts can be lowered by decreasing the alkali amount on the catalyst [38, 39], increasing the space velocity [34], increasing $\mathrm{H}_{2} / \mathrm{CO}$ ratio [36], and decreasing methanol partial pressure [4]. It has been reported that synthesis of higher alcohols are favored within 553-583 K over Cu-based catalysts with promotors [32]. The amounts of esters and ketones are most probably in equilibrium with the corresponding alcohols by hydrogenation, which is strongly affected by the hydrogen partial pressure [4]. Production of ethers such as DME is favored over acidic catalysts and greatly inhibited by water. The catalyst activity towards methanol and higher alcohol synthesis will also be inhibited by water, although Zhao et al. [19] suggested that methanol synthesis is strongly favored in the presence of small amount of water at the beginning of the reaction. Formation of higher alcohols is generally found inhibited by increasing $\mathrm{CO}_{2}$ amount [40]. However, Elliott et al. observed an enhancing effect of $\mathrm{CO}_{2}$ over undoped $\mathrm{Cu}-\mathrm{Zn}$ catalyst [41]. According to Sahibzada et al. [42], methanol production rate over $\mathrm{Cu} / \mathrm{ZnO} / \mathrm{Al}_{2} \mathrm{O}_{3}$ increases linearly with $\mathrm{CO}_{2}$ concentration when $\mathrm{CO}_{2}$ is below $4 \%$. When $\mathrm{CO}_{2}$ is higher than $4 \%$, production of methanol will also be inhibited. Thus, an optimal $\mathrm{CO}_{2}$ concentration should be determined to achieve desired methanol selectivity.

Recent studies especially advances in theoretical calculations have led to deeper understanding of the mechanism of methanol synthesis, which allows fine-tuning the kinetics models for industrial applications. However, knowledge of impurities formation over $\mathrm{Cu} / \mathrm{ZnO} / \mathrm{Al}_{2} \mathrm{O}_{3}$ is relatively scarce. Synthesis of $\mathrm{Cu} / \mathrm{ZnO} / \mathrm{Al}_{2} \mathrm{O}_{3}$ catalysts with minimized impurities such as alkali metals might be a key to control the impurities formation during methanol synthesis.

\section{Conclusions and Future Perspectives}

The progresses made from academia directly benefit catalyst vendors, which generate better catalysts for industrial methanol producers. Operating methanol reactors with a lower initial temperature accompanying with even a higher space time yield is demonstrated. The catalyst lifetime of the latest generation is prolonged than its predecessor, reducing the OPEX further. As the global demand of methanol continues to grow, industrial methanol synthesis is expected to be more prosperous. Although many different strategies are emerging in the innovation of catalyst materials or its composition [43], $\mathrm{Cu} / \mathrm{ZnO} / \mathrm{Al}_{2} \mathrm{O}_{3}$ originally developed by ICI (now Johnson Matthey), is projected to dominate the industrial practice. Future efforts from academia research shall be focused on the following topics to improve methanol synthesis or methanol-involved processes in industry.

(1) The catalyst is deactivated primarily by poisons ( $\mathrm{S}$ and $\mathrm{Cl}$, and etc.), sintering and water. The former can be easily addressed by purification of the feed. However, lower temperatures $(<543 \mathrm{~K})$ favor less sintering and impurity formation at the cost of activity loss. Thus, developing $\mathrm{CO}_{2}$-tolerant catalyst capable of working at a very low temperature will be a breakthrough;

(2) Reducing the CAPEX/OPEX of catalysts can be done by increasing the space time yield of methanol. Optimization of the formulation of each component is one direction to go;

(3) The syngas for methanol synthesis is typically generated at a much lower pressure. Developing a catalyst capable of working at a very much lower pressure will be another breakthrough to significantly reduce plant CAPEX/OPEX;

(4) Trimethylamine formed during the first day of plant operation leads to a failure meeting product specs due to a fishy smell. However, it is impossible to remove by conventional distillation columns. Absorbents are generally used to handle such an impurity issue in industry. Catalysts without residual nitrates are preferred to address such a common issue.

\section{References}

1. Methanol Brochure, Primus Green Energy, Available: http://www.primusge.com/

2. BASF, US Patent 1,569,775, 1923.

3. P. Davies, F.F. Snowdon, G.W. Bridger, D.O. Hughes, P.W. Young, UK Patent 1010871, 1966

4. J.B. Hansen, P.E. Højlund Nielsen, "Methanol Synthesis," in: Handbook of Heterogeneous Catalysis, Wiley-VCH Verlag GmbH \& Co. KGaA, 2008,

5. C.H. Bartholomew, R.J. Farrauto, Fundamentals of Industrial Catalytic Processes, 2nd Edition, Wiley, 2010. 
6. S. Natesakhawat, J.W. Lekse, J.P. Baltrus, P.R. Ohodnicki, B.H. Howard, X. Deng, C. Matranga, "Active Sites and Structure-Activity Relationships of Copper-Based Catalysts for Carbon Dioxide Hydrogenation to Methanol," ACS Catalysis, vol. 2, no. 8, pp. 1667-1676, 2012.

7. A. Le Valant, C. Comminges, C. Tisseraud, C. Canaff, L. Pinard, Y. Pouilloux, "The Cu-ZnO Synergy in Methanol Synthesis from $\mathrm{CO}_{2}$, Part 1: Origin of Active Site Explained by Experimental Studies and a Sphere Contact Quantification Model on Cu+ZnO Mechanical Mixtures," Journal of Catalysis, vol. 324, no. pp. 41-49, 2015.

8. M. Behrens, F. Studt, I. Kasatkin, S. Kühl, M. Hävecker, F. Abild-Pedersen, S. Zander, F. Girgsdies, P. Kurr, B.-L. Kniep, M. Tovar, R.W. Fischer, J.K. Nørskov, R. Schlögl, "The Active Site of Methanol Synthesis over $\mathrm{Cu} / \mathrm{ZnO} / \mathrm{Al}_{2} \mathrm{O}_{3}$ Industrial Catalysts," Science, vol. 336, no. 6083, pp. 893-897, 2012.

9. S. Kuld, M. Thorhauge, H. Falsig, C.F. Elkjær, S. Helveg, I. Chorkendorff, J. Sehested, "Quantifying the Promotion of $\mathrm{Cu}$ Catalysts by ZnO for Methanol Synthesis," Science, vol. 352, no. 6288, pp. 969-974, 2016.

10. C. Tisseraud, C. Comminges, S. Pronier, Y. Pouilloux, A. Le Valant, "The Cu-ZnO Synergy in Methanol Synthesis Part 3: Impact of the Composition of a Selective $\mathrm{Cu} @ \mathrm{ZnO}_{\mathrm{x}}$ Core-Shell Catalyst on Methanol Rate Explained by Experimental Studies and a Concentric Spheres Model," Journal of Catalysis, vol. N/A, no. N/A, pp. N/A, 2016.

11. J.C. Frost, "Junction Effect Interactions in Methanol Synthesis Catalysts," Nature, vol. 334, no. 6183, pp. 577$580,1988$.

12. Y. Liu, C. Liu, X. Deng, W. Huang, "A Study on Deactivation of Cu-Zn-Al Catalyst for Higher Alcohols Synthesis," RSC Advances, vol. 5, no. 120, pp. 99023-99027, 2015.

13. G.H. Graaf, J.G.M. Winkelman, "Chemical Equilibria in Methanol Synthesis Including the Water-Gas Shift Reaction: A Critical Reassessment," Industrial \& Engineering Chemistry Research, vol. 55, no. 20, pp. 5854-5864, 2016.

14. G.C. Chinchen, P.J. Denny, D.G. Parker, M.S. Spencer, D.A. Whan, "Mechanism of Methanol Synthesis from $\mathrm{CO}_{2} / \mathrm{CO} / \mathrm{H}_{2}$ Mixtures over Copper/Zinc Oxide/Alumina Catalysts: Use of 14C-Labelled Reactants," Applied Catalysis, vol. 30, no. 2, pp. 333-338, 1987.

15. K. Klier, "Methanol Synthesis," in: Advances in Catalysis, Academic Press, 1982, pp. 243-313.

16. L.C. Grabow, M. Mavrikakis, "Mechanism of Methanol Synthesis on $\mathrm{Cu}$ through $\mathrm{CO}_{2}$ and $\mathrm{CO}$ Hydrogenation," ACS Catalysis, vol. 1, no. 4, pp. 365-384, 2011.

17. Y. Yang, C.A. Mims, D.H. Mei, C.H.F. Peden, C.T. Campbell, "Mechanistic Studies of Methanol Synthesis over $\mathrm{Cu}$ from $\mathrm{CO} / \mathrm{CO}_{2} / \mathrm{H}_{2} / \mathrm{H}_{2} \mathrm{O}$ Mixtures: The Source of $\mathrm{C}$ in Methanol and the Role of Water," Journal of Catalysis, vol. 298, no. N/A, pp. 10-17, 2013.

18. A.M. Appel, J.E. Bercaw, A.B. Bocarsly, H. Dobbek, D.L. DuBois, M. Dupuis, J.G. Ferry, E. Fujita, R. Hille, P.J.A. Kenis, C.A. Kerfeld, R.H. Morris, C.H.F. Peden, A.R. Portis, S.W. Ragsdale, T.B. Rauchfuss, J.N.H. Reek, L.C. Seefeldt, R.K. Thauer, G.L. Waldrop, "Frontiers, Opportunities, and Challenges in Biochemical and Chemical Catalysis of $\mathrm{CO}_{2}$ Fixation," Chemical Reviews, vol. 113, no. 8, pp. 6621-6658, 2013.

19. Y.-F. Zhao, Y. Yang, C. Mims, C.H.F. Peden, J. Li, D. Mei, "Insight into Methanol Synthesis from $\mathrm{CO}_{2}$ Hydrogenation on $\mathrm{Cu}\left(\begin{array}{lll}1 & 1 & 1\end{array}\right)$ : Complex Reaction Network and the Effects of $\mathrm{H}_{2} \mathrm{O}$," Journal of Catalysis, vol. 281, no. 2, pp. 199-211, 2011.

20. P.B. Rasmussen, P.M. Holmblad, T. Askgaard, C.V. Ovesen, P. Stoltze, J.K. Nørskov, I. Chorkendorff, "Methanol Synthesis on $\mathrm{Cu}(100)$ from a Binary Gas Mixture of $\mathrm{CO}_{2}$ and $\mathrm{H}_{2}$," Catalysis Letters, vol. 26, no. 3-4, pp. 373-381, 1994.

21. P.B. Rasmussen, M. Kazuta, I. Chorkendorff, "Synthesis of Methanol from a Mixture of $\mathrm{H}_{2}$ and $\mathrm{CO}_{2}$ On Cu(100)," Surface Science, vol. 318, no. 3, pp. 267-280, 1994.

22. Y. Yang, C.A. Mims, R.S. Disselkamp, J.-H. Kwak, C.H.F. Peden, C.T. Campbell, "(Non)formation of Methanol by Direct Hydrogenation of Formate on Copper Catalysts," The Journal of Physical Chemistry C, vol. 114, no. 40, pp. 17205-17211, 2010.

23. P.A. Taylor, P.B. Rasmussen, I. Chorkendorff, "Is the Observed Hydrogenation of Formate the Rate-Limiting Step in Methanol Synthesis?," Journal of the Chemical Society, Faraday Transactions, vol. 91, no. 8, pp. 12671269, 1995. 
24. Y. Yang, J. Evans, J.A. Rodriguez, M.G. White, P. Liu, "Fundamental Studies of Methanol Synthesis from $\mathrm{CO}_{2}$ Hydrogenation on $\mathrm{Cu}(111), \mathrm{Cu}$ Clusters, and $\mathrm{Cu} / \mathrm{ZnO}(000), "$ Physical Chemistry Chemical Physics, vol. 12, no. 33, pp. 9909-9917, 2010.

25. Y. Yang, D. Mei, C.H.F. Peden, C.T. Campbell, C.A. Mims, "Surface-Bound Intermediates in LowTemperature Methanol Synthesis on Copper: Participants and Spectators," ACS Catalysis, vol. 5, no. 12, pp. 7328-7337, 2015.

26. G.H. Graaf, E.J. Stamhuis, A.A.C.M. Beenackers, "Kinetics of Low-Pressure Methanol Synthesis," Chemical Engineering Science, vol. 43, no. 12, pp. 3185-3195, 1988.

27. J. Skrzypek, M. Lachowska, H. Moroz, "Kinetics of Methanol Synthesis over Commercial Copper/Zinc Oxide/Alumina Catalysts," Chemical Engineering Science, vol. 46, no. 11, pp. 2809-2813, 1991.

28. K.M.V. Bussche, G.F. Froment, "A Steady-State Kinetic Model for Methanol Synthesis and the Water Gas Shift Reaction on a Commercial Cu/ZnO/ $\mathrm{Al}_{2} \mathrm{O}_{3}$ Catalyst," Journal of Catalysis, vol. 161, no. 1, pp. 1-10, 1996.

29. M. Šetinc, J. Levec, "Dynamics of a Mixed Slurry Reactor for the Three-Phase Methanol Synthesis," Chemical Engineering Science, vol. 56, no. 21-22, pp. 6081-6087, 2001.

30. A.Y. Rozovskii, G.I. Lin, "Fundamentals of Methanol Synthesis and Decomposition," Topics in Catalysis, vol. 22, no. 3-4, pp. 137-150, 2003.

31. K.J. Smith, R.B. Anderson, "The Higher Alcohol Synthesis over Promoted Cu/ZnO Catalysts," The Canadian Journal of Chemical Engineering, vol. 61, no. 1, pp. 40-45, 1983.

32. M. Gupta, M.L. Smith, J.J. Spivey, "Heterogeneous Catalytic Conversion of Dry Syngas to Ethanol and Higher Alcohols on Cu-Based Catalysts," ACS Catalysis, vol. 1, no. 6, pp. 641-656, 2011.

33. J.G. Nunan, C.E. Bogdan, K. Klier, K.J. Smith, C.-W. Young, R.G. Herman, "Higher Alcohol and Oxygenate Synthesis Over Cesium-Doped CuZnO Catalysts," Journal of Catalysis, vol. 116, no. 1, pp. 195-221, 1989.

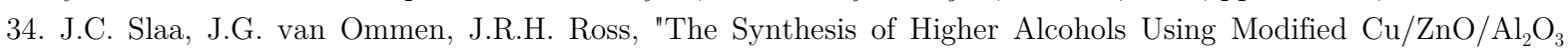
Catalysts," Catalysis Today, vol. 15, no. 1, pp. 129-148, 1992.

35. I. Boz, "Higher Alcohol Synthesis over a K-Promoted $\mathrm{Co}_{2} \mathrm{O}_{3} / \mathrm{CuO} / \mathrm{ZnO} / \mathrm{Al}_{2} \mathrm{O}_{3}$ Catalyst," Catalysis Letters, vol. 87, no. 3-4, pp. 187-194, 2003.

36. V. Mahdavi, M.H. Peyrovi, M. Islami, J.Y. Mehr, "Synthesis of Higher Alcohols from Syngas over Cu$\mathrm{Co}_{2} \mathrm{O}_{3} / \mathrm{ZnO}, \mathrm{Al}_{2} \mathrm{O}_{3}$ Catalyst," Applied Catalysis A: General, vol. 281, no. 1-2, pp. 259-265, 2005.

37. E.M. Calverley, K.J. Smith, "Kinetic Model for Alcohol Synthesis over a Promoted Copper/Zinc Oxide/Chromium Oxide $\left(\mathrm{Cr}_{2} \mathrm{O}_{3}\right)$ Catalyst," Industrial \& Engineering Chemistry Research, vol. 31, no. 3, pp. 792-803, 1992

38. I. Boz, M. Sahibzada, I.S. Metcalfe, "Kinetics of the Higher Alcohol Synthesis over a K-promoted $\mathrm{CuO} / \mathrm{ZnO} / \mathrm{Al}_{2} \mathrm{O}_{3}$ Catalyst," Industrial \&3 Engineering Chemistry Research, vol. 33, no. 9, pp. 2021-2028, 1994.

39. J. Nunan, K. Klier, C.-W. Young, P.B. Himelfarb, R.G. Herman, "Promotion of Methanol Synthesis over $\mathrm{Cu} / \mathrm{ZnO}$ Catalysts by Doping with Caesium," Journal of the Chemical Society, Chemical Communications, vol. no. 3, pp. 193-195, 1986.

40. J.J. Spivey, A. Egbebi, "Heterogeneous Catalytic Synthesis of Ethanol from Biomass-Derived Syngas," Chemical Society Reviews, vol. 36, no. 9, pp. 1514-1528, 2007.

41. D.J. Elliott, "Higher Alcohol Synthesis over CuOZnO Catalysts: Relationship between Methanol and Higher Alcohol Syntheses," Journal of Catalysis, vol. 111, no. 2, pp. 445-449, 1988.

42. M. Sahibzada, I.S. Metcalfe, D. Chadwick, "Methanol Synthesis from $\mathrm{CO} / \mathrm{CO}_{2} / \mathrm{H}_{2}$ over $\mathrm{Cu} / \mathrm{ZnO} / \mathrm{Al}_{2} \mathrm{O}_{3}$ at Differential and Finite Conversions," Journal of Catalysis, vol. 174, no. 2, pp. 111-118, 1998.

43. O. Martin, A.J. Martín, C. Mondelli, S. Mitchell, T.F. Segawa, R. Hauert, C. Drouilly, D. Curulla-Ferré, J. Pérez-Ramírez, "Indium Oxide as a Superior Catalyst for Methanol Synthesis by $\mathrm{CO}_{2}$ Hydrogenation," Angewandte Chemie International Edition, vol. 55, no. 21, pp. 6261-6265, 2016. 